\title{
Debris-flow susceptibility assessment through cellular automata modeling: an example from 15-16 December 1999 disaster at Cervinara and San Martino Valle Caudina (Campania, southern Italy)
}

\author{
G. Iovine $^{1}$, S. Di Gregorio ${ }^{2}$, and V. Lupiano ${ }^{1}$ \\ ${ }^{1}$ CNR-IRPI, via Cavour, 87030 Rende, CS, Italy \\ ${ }^{2}$ Dept. of Mathematics and Centre of High-Performance Computing, University of Calabria, 87036 Arcavacata di Rende, CS, \\ Italy
}

Received: 2 August 2002 - Revised: 15 November 2002 - Accepted: 25 November 2002

\begin{abstract}
On 15-16 December 1999, heavy rainfall severely stroke Campania region (southern Italy), triggering numerous debris flows on the slopes of the San Martino Valle Caudina-Cervinara area. Soil slips originated within the weathered volcaniclastic mantle of soil cover overlying the carbonate skeleton of the massif. Debris slides turned into fast flowing mixtures of matrix and large blocks, downslope eroding the soil cover and increasing their original volume. At the base of the slopes, debris flows impacted on the urban areas, causing victims and severe destruction (Vittori et al., 2000).

Starting from a recent study on landslide risk conditions in Campania, carried out by the Regional Authority (PAI Hydrogeological setting plan, in press), an evaluation of the debris-flow susceptibility has been performed for selected areas of the above mentioned villages. According to that study, such zones would be in fact characterised by the highest risk levels within the administrative boundaries of the same villages ("HR-zones"). Our susceptibility analysis has been performed by applying SCIDDICA $S_{3-h e x}-$ a hexagonal Cellular Automata model (von Neumann, 1966), specifically developed for simulating the spatial evolution of debris flows (Iovine et al., 2002). In order to apply the model to a given study area, detailed topographic data and a map of the erodable soil cover overlying the bedrock of the massif must be provided (as input matrices); moreover, extent and location of landslide source must also be given.

Real landslides, selected among those triggered on winter 1999, have first been utilised for calibrating SCIDDICA $S_{3-h e x}$ and for defining "optimal" values for parameters. Calibration has been carried out with a GIS tool, by quantitatively comparing simulations with actual cases: optimal values correspond to best simulations. Through geological evaluations, source locations of new phenomena have then
\end{abstract}

Correspondence to: G. Iovine (iovine@irpi.cs.cnr.it) been hypothesised within the HR-zones. Initial volume for these new cases has been estimated by considering the actual statistics of the 1999 landslides. Finally, by merging the results of simulations, a deterministic susceptibility zonation of the considered area has been obtained. In this paper, aiming at illustrating the potential for debris-flow hazard analyses of the model SCIDDICA $S_{3-h e x}$, a methodological example of susceptibility zonation of the Vallicelle HR-zone is presented.

\section{Introduction}

Debris flows (Johnson and Rodine, 1984) pose serious risk conditions in urbanised geological contexts characterised by high relief energy, loose soil cover and by suitable triggering processes - mainly heavy rainfall, earthquakes, and snowthawing (Eisbacher and Clague, 1984; Wieczorek, 1996; Schuster and Wieczorek, 2002). In performing landslide hazard analyses (Varnes and IAEG, 1984), the time of occurrence and the location of a given phenomenon should first be hypothesised. In case of a soil slip-debris flow, the downslope propagation ("run-out") of the flow-component should also be evaluated (Ellen, 1988; Cannon and Savage, 1988; Cannon, 1989).

With the aim of facing the problem of evaluating the spatial evolution of a given soil slip-debris flow, once its source location and dimension have been defined, the Cellular Automata model SCIDDICA $S_{3}$ has recently been developed (Iovine et al., 2002). In the present paper, an example of application of its hexagonal release $\left(S_{3-h e x}\right)$ to the "Vallicelle" area of study (San Martino Valle Caudina - Campania, southern Italy) is briefly described: by adopting an empirical methodology, based on geological analyses, the debris-flow potential (susceptibility) of the study area has been quantita- 


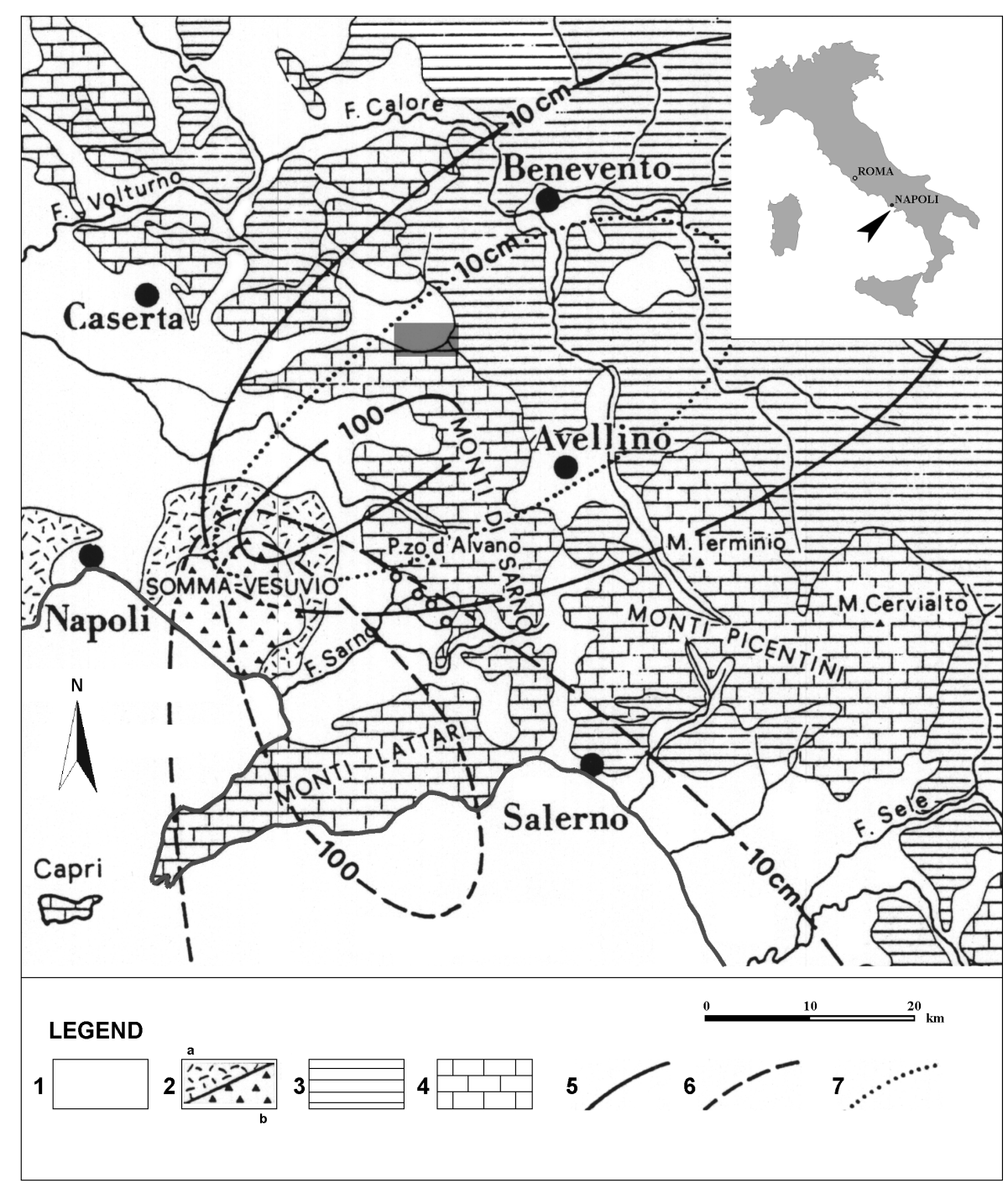

Fig. 1. Schematic geological map of the study area (after Del Prete et al., 1998, mod.). Key: (1) alluvial sediments; (2) pyroclastic terrain (a) and lava (b); (3) clay, marl and sandstone; (4) carbonate; (5-7) isopleths (in cm) of the Somma-Vesuvius air-fall deposits of year 1800 B.C. (5), 79 A.D. (6) and 472 A.D. (7). In grey, the Cervinara-San Martino V. C. area of study.

tively evaluated through cellular automata modelling. Nevertheless, as the field surveying and the model validation are still in progress in the study area, both the collection of geological information and the determination of the best set of parameters have not been completed yet. The results here presented, in terms of susceptibility zonation, should then be considered only as a methodological example.

\section{The study area}

The study area is located on the southern border of the Caudina Valley, on the northern slope of the Partenio-Monti di Avella massif, about $20 \mathrm{~km}$ from the towns of Avellino and Salerno (Campania, southern Italy - Figs. 1 and 2). Mesozoic carbonate rocks, belonging to the Alburno-Cervati Unit, constitute the skeleton of the massif (Ippolito et al., 1975). The relief consists of a NE-dipping monocline, made of thick limestone beds characterised by notable angle of dip (35$70^{\circ}$ ). The bedrock is overlain by Miocene-Pliocene terrigenous terrains belonging to the Irpine Units (Ippolito et al., 1975). A mantle of heterogeneous residual and colluvial soils, derived from Quaternary Somma-Vesuvius and Phlegrean pyroclastic terrains (mainly from the Avellino eruption - described by Lirer et al., 1973 - and the Campanian Ignimbrite - described by Rosi and Sbrana, 1987, respectively), overly the above mentioned rocks. These volcaniclastic terrains, mainly constituted by pumiceous and ashy levels alternated with buried soils, show variable thickness (up to few meters) and geotechnical properties, according to characteristics of the parent eruption and to successive weathering and geomorphic evolution (Fiorillo et al., 2001).

At the base of the massif, thick colluvial and alluvial deposits mark the transition to the Caudina Valley; here, at the mouth of the drainages, debris fans (mainly constituted by 


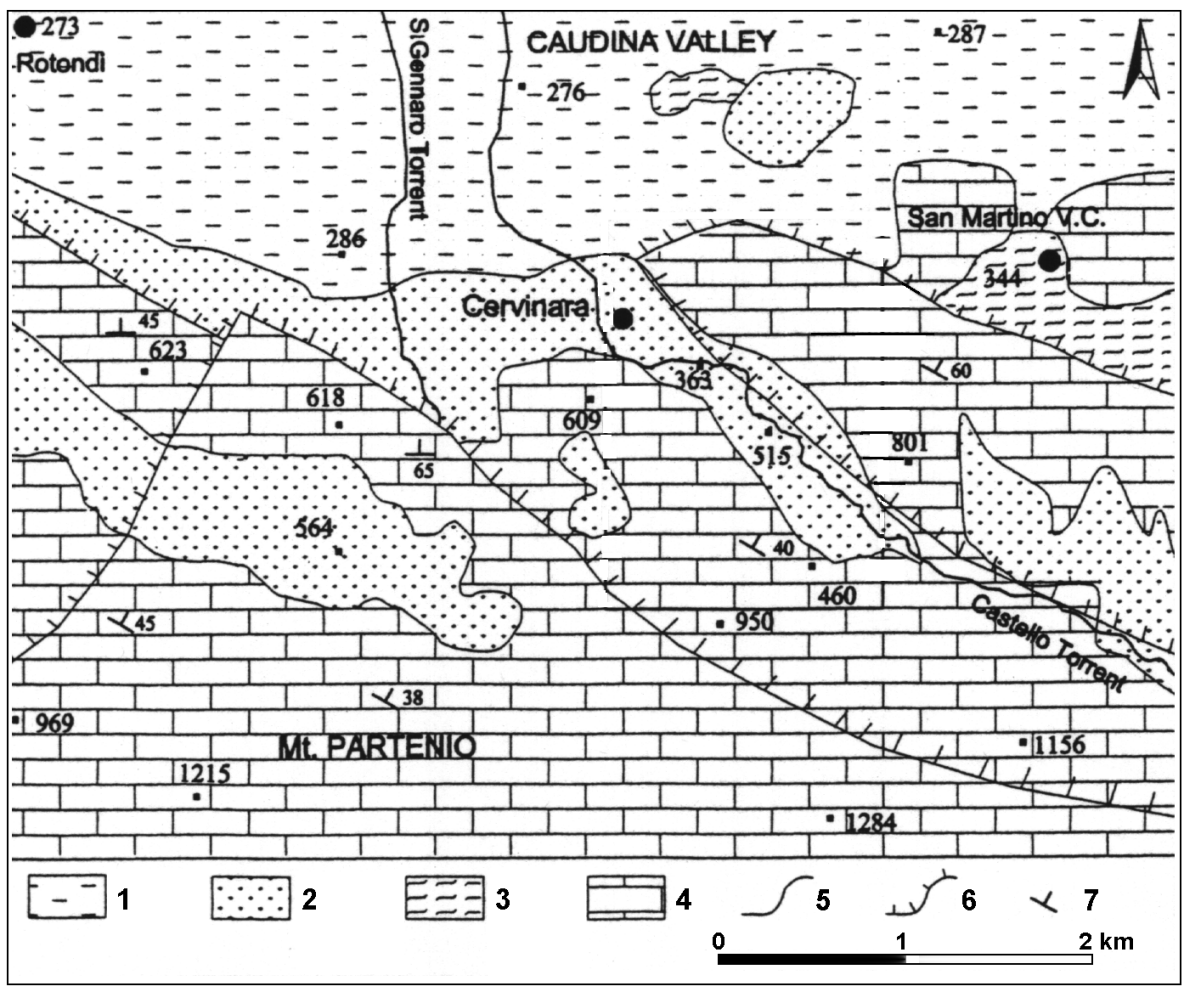

Fig. 2. Geological sketch of the Cervinara-San Martino V. C. area (after Fiorillo et al., 2001, mod.). Key: (1) alluvial deposits (Pleistocene); (2) ignimbrite deposits (35000 y B. P.); (3) terrigenous deposits (Miocene-Pliocene); (4) carbonate rocks (Mesozoic); (5) lithologic limit; (6) main fault; (7) bedding attitude.

debris-flow deposits) spread towards the plain. Along the base of the massif, several villages are to be found: among these, Cervinara and San Martino V. C. were in particular affected by the landslides of the December 1999 hydrogeological event.

\section{Landslide activations in the study area on December 1999}

On 15-16 December 1999, heavy rainfall severely stroke Campania region, triggering numerous debris flows on the slopes of the Monti di Avella massif (Vittori et al., 2000). Several soil slips originated on the slopes of the Vallone Castello (Cervinara) and Mt. Pizzone (San Martino V. C.), within the weathered volcaniclastic mantle (Fig. 3); these landslides turned into fast flowing mixtures of matrix and large blocks, downslope eroding the soil cover and increasing their original volume. At the base of the slopes, debris flows impacted on the cited urban areas, causing victims and severe destruction. In particular, three main landslides were triggered on the northern slope of Mt. Pizzone, in the Vallicelle study area (cf. A-C in Fig. 4), and propagated towards the urbanised sector of San Martino V. C.: the easternmost of these (C) caused one victim along the municipal road (a young man who was approaching with a mechanical shovel the base of the slope, in order to help cleaning the mud there accumulated in the first phase of the event), stopping few meters below.

A detailed analysis of the December 1999 disaster has first been carried out, by interpreting air-photographs and through geologic-geomorphologic field surveying. In particular, all the landslides of the 1999 event - and any older evidence which could be identified - have been mapped on 1:5000 scale topographic sheets (Iovine et al., unpublished). Type and amount of soil cover, available for the process of erosion during the movement of the landslide, have also been surveyed in the field (particularly, along the path of the 1999 debris flows). Similarly, evidence related to triggering mechanisms, downslope development and rheology, erosive character, etc. has also been considered. In this way, statistics of the 1999 event have been obtained, which helped (together with data on previous landslide activations, cf. 5.2) in hypothesising characters of future phenomena in the same area.

\section{Cellular Automata modelling of debris flows: SCID- DICA S3}

Cellular Automata (" $C A$ ") are an example of parallel computing model (von Neumann, 1966; Wolfram, 2002): they can be usefully applied for simulating natural phenomena which satisfy the "a-centric" paradigm - i.e. that can be modelled in terms of local interactions among its elementary por- 


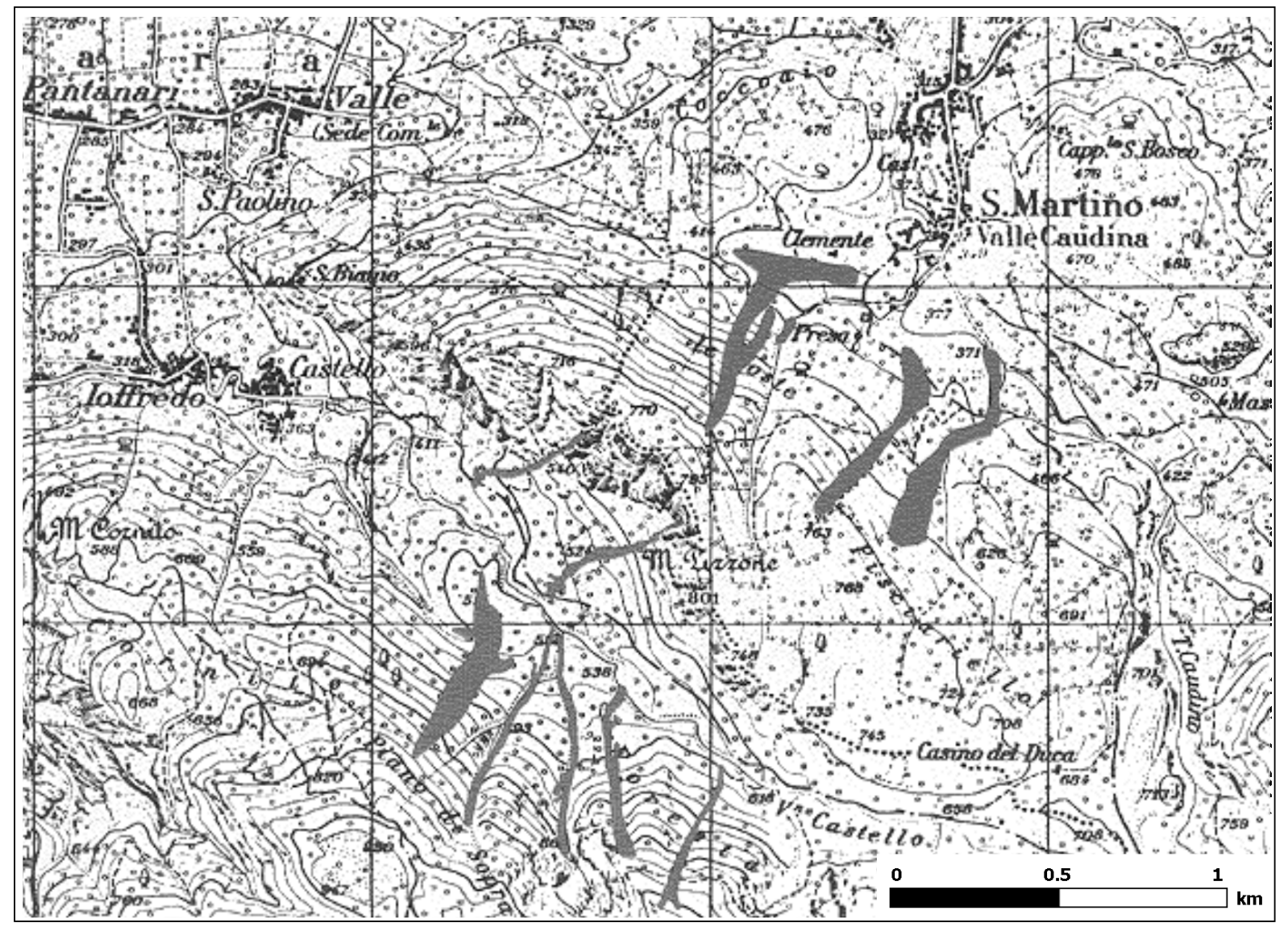

Fig. 3. Principal landslides (in grey) triggered in the Cervinara-San Martino V.C. area on 15-16 December 1999 (after Amanti et al., 1999). The Vallicelle HR-zone lies on the upper-right side of the figure, on the NE slope of Mt. Pizzone, right above the village of San Martino V. C.: here, three main soil slips-debris flows were triggered by the considered hydrogeological event. On the same occasion, seven more landslides were triggered on the flanks of the Vallone Castello area, SE of the Ioffredo-Castello hamlets of Cervinara.

tions (Petitot, 1977). Flow-type landslides (e.g. debris flows) do satisfy the a-centric requirement.

A distinctive characteristic of $C A$ is the possibility of obtaining complex "global" behaviours by means of simple purely "local" rules. They are based on a regular tessellation of the space into a matrix of cells (the cellular space). Each cell of the cellular space has a fixed shape and size, and embeds an identical finite automaton, whose input is given by the states of the neighbouring cells. Cell attributes (substates) describe the physical characteristics of that portion of space.

In the last decades, $C A$ proved to be a valid alternative to differential equations in simulating complex natural phenomena (Toffoli, 1984; Di Gregorio and Serra, 1999). In particular, attempts of simulating flow-type landslides have recently been carried out by several authors, also through $C A$ models, with satisfactory results (Barca et al., 1986; Segre and Deangeli, 1995; Malamud and Turcotte, 2000; Clerici and Perego, 2000). Among these efforts, the $C A$ model SCIDDICA was developed for first simulating the Tessina slow-moving earth flow (release "T", Avolio et al., 2000). Nevertheless, depending on its kinetic energy, a landslide can also show significant inertial properties (e.g. can move upward, along a slope, and override obstacles). Accordingly, the original code was modified: the "run-up" was added to the model, and the case of study of the Mt. Ontake debris avalanche was analysed (release “O”, Di Gregorio et al., 1994; Di Gregorio et al., 1999).

After the May 1998 disaster in Campania (Del Prete et al., 1998), the model has further on been extended (family " $S$ "), in order to consider some peculiar features of rapid debris flows. First of all, as the amount of material eroded along the path of a debris flow can usually be significant (greatly increasing the initial volume of the soil slip), the process of erosion of the regolith overlying the bedrock has been included into the model (release $S_{1}$, Avolio et al., 1999; D'Ambrosio et al., 2003). Moreover, the original mechanism of distribution of the landslide debris among the central cell and the neighbouring ones has been improved (release $S_{2}$, D'Ambrosio et al., 2002; Iovine and Di Gregorio, 2003). The need for simulating the process of "progressive" erosion of the regolith has led to further modifications and the release $S_{3}$ has thus been obtained. In the hexagonal release here utilised $\left(S_{3-h e x}\right)$, the possibility of triggering of multiple soils slips has also been implemented (for more details, 


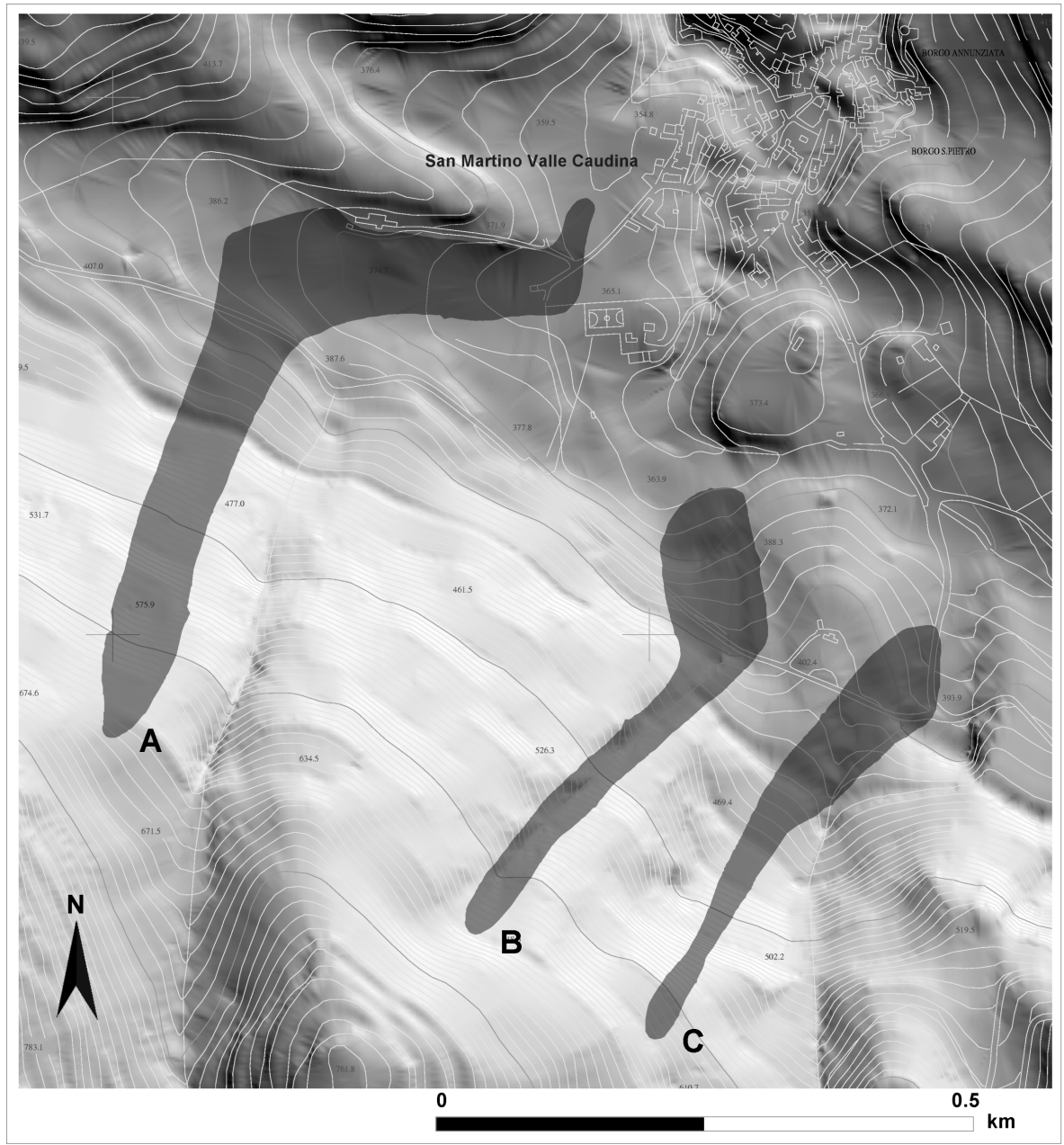

Fig. 4. The Vallicelle (San Martino V. C.) debris flows of December 1999: from left to right, the cases of study A-C utilised in the calibration phase of SCIDDICA $S_{3-\text { hex }}$ (after PAI-Hydrogeological setting plan, in press).

cf. Iovine et al., 2002).

The transition function $(\sigma)$ of the model is made of a set of rules: these are derived by subdividing the phenomenon into independent elementary processes. Elementary processes can develop either within a given cell (internal transformations) or as a consequence of local interactions with the neighbouring cells. At this purpose, an appropriate neighbourhood must be selected, by adopting a geometrical pattern of cells - which is invariant in time, and constant for all the cells. The neighbourhood considered in the present release is shown in Fig. 5. In particular, three elementary processes constitute the transition function of the model, which are locally evaluated at each step of computation: (1) debris distribution among the cells, according to pressure gradients across the cells and to flow rheology; (2) run-up determination, used for evaluating the landslide ability of moving upslope; (3) mobilisation of the soil cover (i.e. erosion and transformation into landslide material, according to the energy of the flowing mass).

At the beginning of each simulation, the substates of the cells are initialised by means of input matrices. In this way, location and the extent of each landslide source to be simulated are specified, together with the thickness of regolith. This latter overlies the bedrock and can be eroded by the flowing debris: it must then be considered for computing changes to the original volume of the landslide. Values of global parameters are also assigned in this phase (cf. list in Table 1): note that they are not allowed to change during the simulation. The transition function is then simultaneously applied, step by step, to all the cells in R: by properly combining each elementary "effect" (produced by each elementary process), the evolution of the system can be simulated.

It should be stressed that, in the $C A$ environment, classic Natures' laws must be suitably rewritten in a discrete context (Toffoli, 1984): as a consequence, the parameters of the formulae of the classic approach do not always strictly relate to those of the local rules of the $C A$ transition function. Owing to the peculiarity of the $C A$ approach, which involves "discretisation", values of global parameters do not correspond to actual physical figures: they are to be considered as the optimal combination of model parameters, which allows the model to better simulate the phenomenon. Basic princi- 
Table 1. SCIDDICA S3-hex: list of global parameters

\begin{tabular}{|c|c|c|c|}
\hline Parameter & Meaning & \multicolumn{2}{|c|}{ Optimal values } \\
\hline$p_{a}$ & Apothem of the cell (in meters) & \multicolumn{2}{|c|}{1.25} \\
\hline$p_{a d h}$ & $\begin{array}{l}\text { Adhesion (the unmovable amount } \\
\text { of landslide debris, in meters) }\end{array}$ & \multicolumn{2}{|c|}{0.001} \\
\hline$p_{f}$ & $\begin{array}{l}\text { Threshold for outflows of landslide debris } \\
\text { (height in meters, related to friction angle) }\end{array}$ & \multicolumn{2}{|c|}{0.1} \\
\hline$p_{r}$ & $\begin{array}{l}\text { Relaxation rate of debris outflows } \\
\text { from the central cell }\end{array}$ & \multicolumn{2}{|c|}{1} \\
\hline$p_{r l}$ & $\begin{array}{l}\text { Run-up loss, at each step } \\
\text { (owing to frictional dissipation), in meters }\end{array}$ & 0.6 & 1.5 \\
\hline$p_{m t}$ & $\begin{array}{l}\text { Activation threshold for mobilisation } \\
\text { (in square meters) }\end{array}$ & 3.5 & 2.0 \\
\hline$p_{p e f}$ & Factor of progressive erosion & 0.015 & 0.065 \\
\hline
\end{tabular}

ples of physics (e.g. principles of conservation) are indeed present in the $C A$ approach: they are just expressed in a different way. For instance, the minimisation algorithm, which has here been adopted for computing the distribution of the debris among the cells, is based on an equilibrium principle (as described in Di Gregorio and Serra, 1999; Iovine et al., 2002).

\section{Susceptibility evaluation for the "Vallicelle" area}

The release $S_{3-h e x}$ has been tested, by considering several real cases of debris flows recently triggered in Campania (southern Italy): encouraging results have first been obtained by simulating the landslides occurred on May 1998 at Sarno (Iovine et al., 2002). The model has subsequently been tested on the landslides triggered at Cervinara and San Martino V. C. during the December 1999 hydrogeological event.

According to a recent study on landslide risk conditions in Campania, carried out by the Regional Authority (PAI Hydrogeological setting plan, in press), the Vallicelle area of San Martino V.C. would be one of the HR-zones, i.e. characterised by the highest risk levels within the administrative boundaries of the same village. An example of debris-flow susceptibility analysis has then been carried out by applying SCIDDICA $S_{3-h e x}$ to the Vallicelle HR-zone.

Topographic data (1:5000 scale) plus a map of the soil cover have been given to the model as input matrices. Type and amount of regolith have been collected through field surveying: in particular, the amount of erodable debris, overlying the bedrock, has been mapped in terms of thickness of regolith. The predisposition of the soil cover to be eroded by the flowing mass has been empirically estimated in the field, by means of visual inspection and expeditious cementation tests, along the paths of the December 1999 landslides.

\subsection{Validation of the model}

As a rule, in order to apply the model to a given study area for predictive purposes, it must be first validated: in other

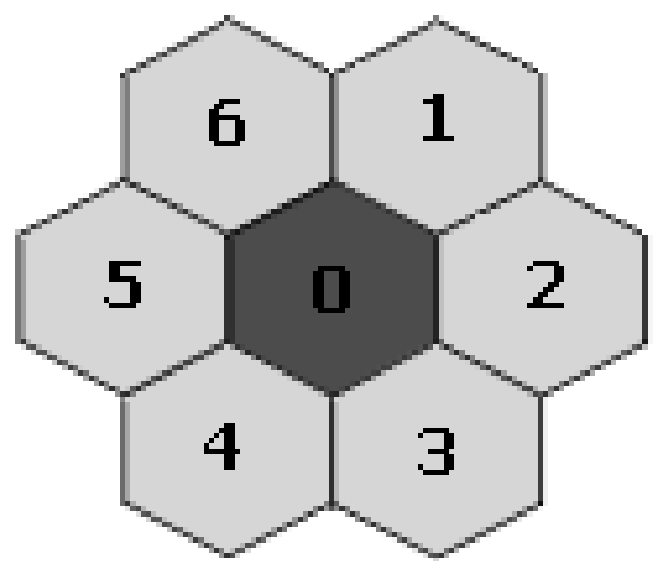

Fig. 5. The hexagonal neighbourhood adopted in the present implementation of SCIDDICA $S_{3-h e x}$ (apothem $=1.25 \mathrm{~m}$ ). Indices (1-6) univocally identify any cell of the neighbourhood (in light grey); the central cell (0) is evidenced in dark grey.

words, the "optimal" set of values for the global parameters of the model have to be determined. This can be achieved through back-analysis, by considering real landslide events of the same type, occurred in the same area or in a very similar geologic context.

In a first step, the calibration can be carried out by considering real cases of landslide, for which detailed morphometric and stratigraphic/sedimentologic data are available. Commonly, only a subset (e.g. 75\%) of the whole sample of landslides is utilised, and the model is first applied by selecting "reasonable" values for the global parameters (also by taking into account the analyses performed into analogous areas of study). In a quantitative way, the results of simulation are then compared to the "real" maps by means of a GIS, and the performance can be evaluated through indicators of error. New simulations are carried out, by changing the global parameters - until satisfying results are obtained (i.e. when the results show errors smaller than prefixed thresholds). In a second step, the model is validated by simulating the remaining sample of landslides (i.e. those not considered for calibration) and by critically evaluating the results by means of the same indicators.

In the present analysis, the model has preliminarily been calibrated for the Vallicelle HR-zone, by considering the three principal landslides there triggered on December 1999: location and extent of the source areas have been considered, and the model has been applied to each landslide.

The adopted procedure for calibration is as follows:

1. initial values have been assumed for the global parameters, also on the base of the values previously determined in other similar study areas (e.g. the Sarno-Pizzo d'Alvano area, in Campania);

2. results of simulation have been quantitatively analysed (in a GIS environment), by comparing the map of the real cases with the simulated ones. At this purpose, in- 
Table 2. Calibration of the model: indicators of error

\begin{tabular}{cccc}
\hline & case A & case B & case C \\
\hline area of real landslide $(R$, in square meters) & 54063 & 25006 & 20213 \\
area of simulated landslide $(S$, in square meters) & 78446 & 20046 & 36476 \\
$R \cap S$ (in square meters) & 49295 & 19284 & 16609 \\
$R \cup S$ (in square meters) & 83214 & 25768 & 40080 \\
$e_{1}=\sqrt{\frac{R \cap S}{R \cup S}}$ & 0.77 & 0.86 & 0.64 \\
$e_{2}=\sqrt{\frac{R \cap S}{R}}$ & 0.95 & 0.88 & 0.91 \\
\hline
\end{tabular}

dicators of error (cf. Table 2) have been defined, by evaluating the landslide-affected area predicted by the model and any difference with the real case. The comparison has been performed by verifying the areas affected by both cases (the real and the simulated), and those affected by only one of them. Moreover, the erosion/deposition character of the flow has also been taken into account, in order to better evaluate the performed simulations.

3. On the base of a trial-and-error method, values of parameters have been modified, aiming at obtaining better results (in terms of indicators of error) through new simulations. In this way, "optimal" values for the parameters of the model have been iteratively determined through back-analysis, by systematically comparing the results of simulation with the map of the real cases. Simulations were judged "acceptable" only when the above mentioned indicators showed values not exceeding pre-fixed thresholds.

Generally speaking, the quality of a simulation can be evaluated by comparing areas affected by the landslide in the real (" $R$ ") and the simulated (" $S$ ") cases. At this purpose, a primary indicator of error $\left(e_{1}\right)$ has been defined, according to the following formula:

$e_{1}=\sqrt{\frac{R \cap S}{R \cup S}}$

where

- the intersection operation $(\cap)$ individuates the area which is in common between the real and the simulated cases;

- the union operation $(\cup)$ accounts for the area superposition of $R$ and $S$.

As areas are considered in the evaluation of the indicator of error, square root operation is needed for normalisation (cubic roots would be needed for volumes). The indicator $e_{1}$ ranges between 0 (i.e. complete unsuccess of simulation) and 1 (i.e. perfect simulation). It accounts well also for intermediate cases: e.g. a simulation covering all the area of the real case will have a score which is small, as far as the simulated area exceeds the real case $(S \gg R)$. Moreover, in case of a simulation perfectly included into the real case, the indicator $e_{1}$ will have again a small value, as far as the real area is more extended than the simulated one $(R \gg S)$.

An acceptability threshold can be fixed, depending on empirical considerations (as commonly done in statistical analysis). In the case here presented, a value of 0.7 could represent such a threshold for $e_{1}$, given the quality of the morphologic data available and also the preliminary phase of analysis performed. A supplementary indicator of error $\left(e_{2}\right)$ may also be considered, defined as:

$e_{2}=\sqrt{\frac{R \cap S}{R}}$

where symbols and range are the same as in the Eq. (1). The value of $e_{2}$ will be high, if the area of the real landslide $(R)$ is included into the simulated one $(S)$. For this indicator, an acceptability threshold can be fixed as 0.85 .

Note that, as the model can be reliably applied only outside the urbanised sectors, $R$ and $S$ must be computed within a reference area (delimited by dashed lines in Figs. 6 and 7): in other words, areas which can be considered in the analyses lies above the village and extend from the source zone to the base of the slope.

As all the three main landslides triggered in the Vallicelle area on December 1999 have been considered in the calibration phase, the cited optimal parameters allow the best results for all the landslides considered as a whole (smallest being the difference between the simulated and the real cases). Note that we prefer to call them "optimal" and not "best" values as, at present, the validation phase has not been terminated yet. In fact, the required parallel environment is still not available, and the calibration has provisionally been performed on a standard PC platform, by manually assigning initial values to the parameters, and by modifying them on the basis of the analysis of the results. Moreover, only three real cases are available for the considered study area: for validation purposes, a greater sample would be preferable. This limit could be overcome by extending the study area to similar zones, also affected by similar debris flows (e.g. the Vallone Castello zone, Cervinara).

In Fig. 6, the map of the thickness of regolith utilised in the calibration phase is shown, by means of grey-scale. In Fig. 7 , the comparison among real landslides and "best" simulations is shown; obtained values of indicators of error are listed in 


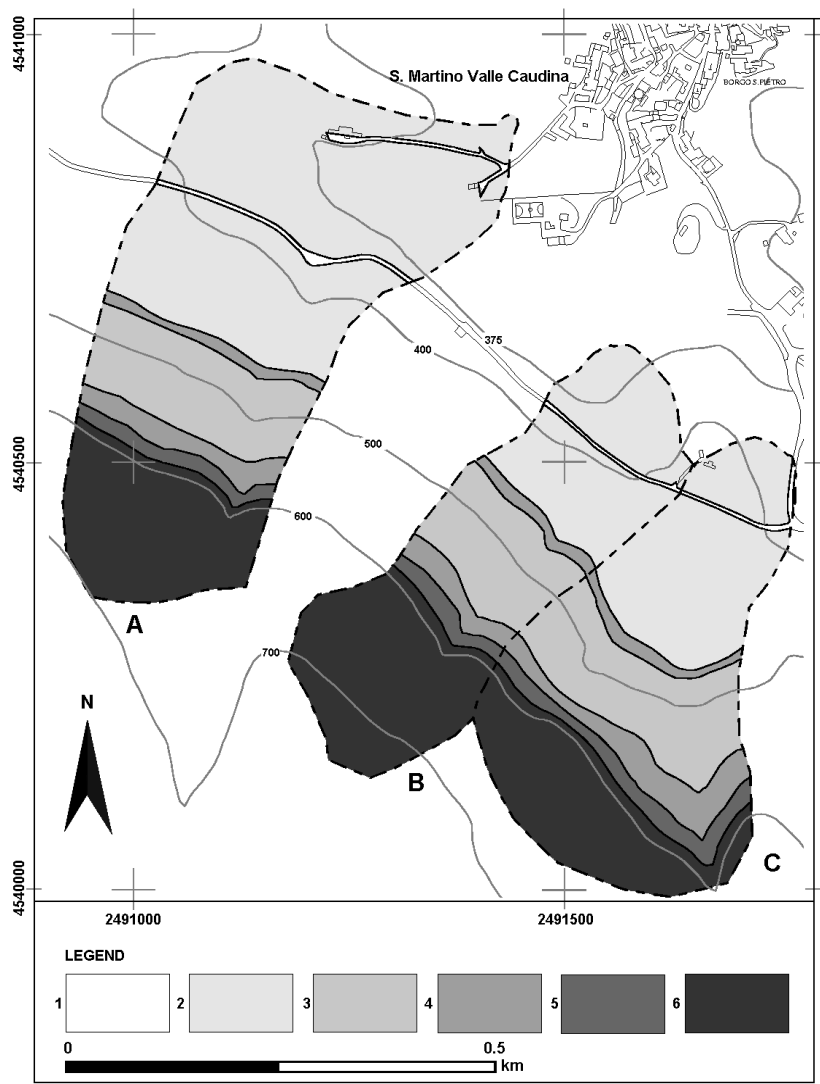

Fig. 6. The Vallicelle area of study: thickness of the regolith utilised for calibration. Key: (1) $0 \mathrm{~m}$ (bedrock outcrop, cemented soil cover, and urbanised area); (2) $0.2 \mathrm{~m}$; (3) $0.5 \mathrm{~m}$; (4) $1 \mathrm{~m}$; (5) $1.5 \mathrm{~m}$; (6) $2 \mathrm{~m}$. Assumed thickness has been extrapolated after detailed field surveying along the paths of the December 1999 landslides (cases $\mathrm{A}-\mathrm{C}$ in Fig. 4). Dashed line delimits the areas considered for the calibration of the A-C cases.

Table 2. If we consider the cases A and B, acceptable results have been obtained for both the considered indicators of error $\left(e_{1}\right.$ and $\left.e_{2}\right)$. As regards the case $\mathrm{C}$, an acceptable score has been obtained only for the indicator $e_{2}$. Accordingly, the overall predictive ability of the model in the Vallicelle area of study can, at present, be considered satisfying. SCIDDICA $S_{3-h e x}$ can then reasonably be applied - even if only for the sake of methodological exemplification - for assessing the debris-flow susceptibility of the considered area. Better morphological data and detailed stratigraphic information would certainly allow an improvement of the values obtained for indicators of error. Moreover, the model performance would certainly benefit from a systematic and automated validation - e.g. in a parallel environment, by means of genetic algorithms: in this way, a proper definition of the "best" values to be assigned to the model parameters could in fact be attained.

\subsection{An example of application for susceptibility zonation}

Through geological and geomorphologic evaluations, source locations of $\mathrm{n} .12$ landslide phenomena have been hypothe-

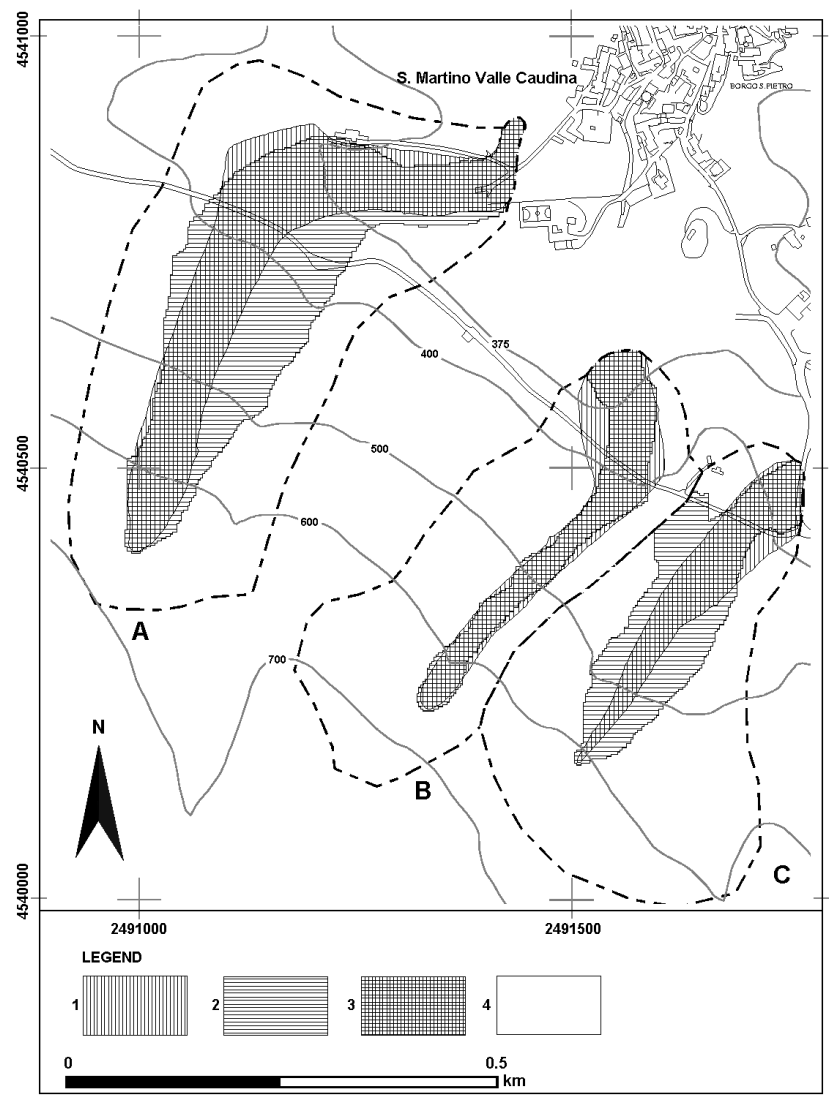

Fig. 7. The Vallicelle area of study: analytical comparison (in ARC/INFO) among the December 1999 landslides (cf. A-C in Fig. 4) and performed "best" simulations. For each of the considered landslides, the area (" $R$ ") affected by the real case (1) has been compared with (2) that obtained through simulation ("S"); 3 ) area correctly simulated (affected by the real case and involved in the simulation); 4) area not affected by the real case and not involved into the simulation. A quantitative comparison, within the same dashed areas of Fig. 6, has been carried out in a GIS environment: numerical results are listed in Table 2.

sised within the Vallicelle HR-zone (note that cases A, B and C of Fig. 4 correspond to cases 1, 7 and 10 in Fig. 8, respectively). Initial volume and location for these new cases has been estimated also by considering the actual statistics of the 1999 hydrogeological event: in other words, it has been assumed that the severity of the hypothesised event (to be modelled by applying SCIDDICA $S_{3-h e x}$ ) should be similar to the 1999 one, in the Vallicelle HR-zone, in terms of type and entity of landslide activations; it would be more severe, in terms of number of landslide activations.

Source locations have been chosen by taking into consideration those of the 1999 landslides, older evidence of landslide and the apexes of the HR-zone (as mapped by the Regional Authority - cf. PAI - Hydrogeological setting plan, in press). In Table 3, some details on the source areas hypothesised in the Vallicelle HR-zone are given; the last 2 rows list average and standard deviations (in parenthesis, values computed excluding source 1). It must be stresses 


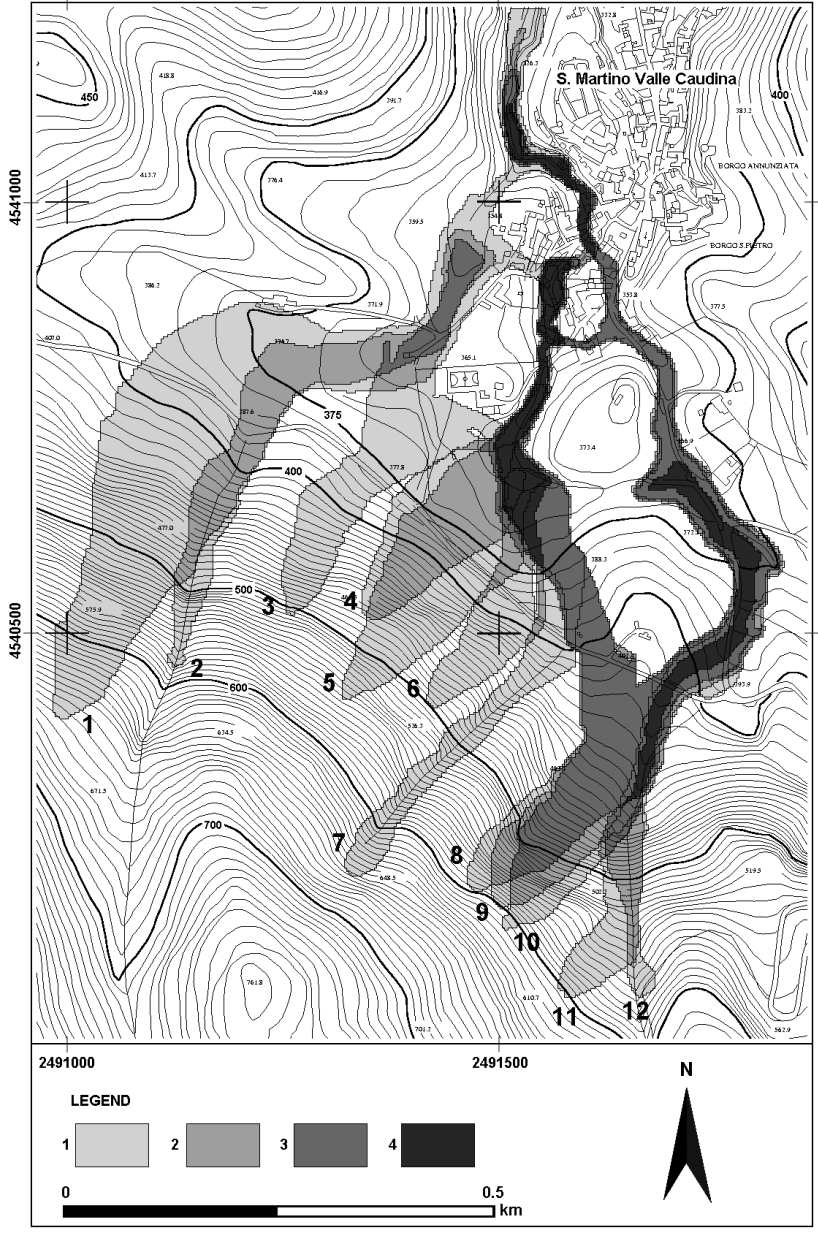

Fig. 8. The Vallicelle area of study: example of debris-flow susceptibility zonation using SCIDDICA $S_{3-\text { hex }}$. On the whole, n. 12 landslide sources have been considered (cf. Table 3): three of them correspond to the December 1999 debris flows (id. 1, 7, and 10); the remaining sources have been selected by considering evidence of pre-1999 landslide events (id. 3, 5, and 8) and by taking into account the landslide-risk zonation recently carried out by the Regional Authority (id. 2, 4, 6, 9, 11, and 12; cf. PAI-Hydrogeological setting plan, in press).

that the considered sample of landslides is not strictly homogeneous: six of them are real cases, triggered either by the December 1999 event (id. 1, 7 and 10) or by previous historic events (id. 3, 5 and 8); the remaining sources have been hypothesised on the base of geological considerations (id. 2, 4, 6, 9, 11 and 12). Moreover, field evidence suggest a peculiar development for the phenomenon 1: the original source would be in fact located in the middle portion of the slope; after the first slide of soil, the scarp migrated several meters upslope (retrogressively), significantly modifying the initial morphometry of the source. On the other hand, the mechanism of landslide development associated to the other surveyed phenomena (and assumed for those hypothesised) would be "normal", from the scarp downslope. Accordingly, morphometric characters of the considered sample reflect the
Table 3. Morphometric characters of the considered landslide sources

\begin{tabular}{ccccc}
\hline $\begin{array}{c}\text { landslide id. } \\
-\end{array}$ & $\begin{array}{c}\text { length } \\
\mathrm{m}\end{array}$ & $\begin{array}{c}\text { thickness of soil cover } \\
\mathrm{m}\end{array}$ & $\begin{array}{c}\text { area } \\
\mathrm{m}^{2}\end{array}$ & $\begin{array}{c}\text { volume } \\
\mathrm{m}^{3}\end{array}$ \\
\hline 1 (A) & 18,6 & 2 & 355,6 & 711,2 \\
2 & 6,3 & 1 & 93,9 & 93,9 \\
3 & 9,8 & 0,5 & 92,4 & 46,2 \\
4 & 6,5 & 0,5 & 100,2 & 50,1 \\
5 & 8,7 & 0,5 & 96,2 & 48,1 \\
6 & 6,9 & 0,5 & 98,9 & 49,45 \\
7 (B) & 7,5 & 2 & 109,6 & 219,2 \\
8 & 7 & 2 & 107,2 & 214,4 \\
9 & 5,7 & 2 & 97,3 & 194,6 \\
$10(\mathrm{C})$ & 6,9 & 2 & 94,3 & 188,6 \\
11 & 5,7 & 2 & 99,7 & 199,4 \\
12 & 5,7 & 1 & 96 & 96 \\
average & 7.9 & 1.3 & 120.1 & 175.9 \\
& $(7.0)$ & $(1.3)$ & $(98.7)$ & $(127.3)$ \\
st. dev. & 3.6 & 0.7 & 74.3 & 183.2 \\
& $(1.3)$ & $(0.7)$ & $(5.4)$ & $(75.2)$ \\
\hline
\end{tabular}

mentioned heterogeneity. Each of the 12 landslides has been simulated "alone", in order to estimate its own propagation path. In other simulations (here not considered), landslides have been allowed to start together - aiming at evaluating the relative interference of coalescing phenomena, also in terms of volume/discharge and impact potential at the base of the massif. Results of simulations have been merged into a single map, aiming at depicting a deterministic susceptibility zonation of the study area.

In Fig. 8, the resulting zonation is shown, by assigning different grey-tones to zones affected by one/more simulated phenomena: some sectors are affected by only one of the simulated landslides, while others are involved in more phenomena (up to seven). More in detail, the areas affected by only one/few landslides are mainly located in the upper portion of the study area, along the NE slope of Mt. Pizzone. Except for cases of conterminous landslides, which can affect the same area, the areas involved into multiple phenomena are generally located at the base of the slope, either along the main drainages or in the large valley right above the village of San Martino V. C. In particular, the sectors located on both sides of the playground, and the road which connects the village to the Vallicelle area (i.e. where one victim was caused by one of the December 1999 debris flows) resulted to be the most susceptible to debris flows.

Note that, as the results obtained by contemporarily simulating adjacent phenomena have not been considered in this phase of the project, the zonation shown in Fig. 8 should be considered, in this respect, only as a "minimum" scenario. 


\section{Discussion}

Landslide hazard assessment requires the evaluation of time of occurrence and location of a given phenomenon, once its dimension and severity have been defined, as well as both the area and the temporal window which the prevision is referred to (Varnes and IAEG, 1984). In case of a debris flow, the assessment of the "initial" characters of the landslide is commonly not enough: this type of phenomenon can in fact travel very far from the source area, either along open slopes or in channels, and is commonly able to erode materials along the path, thus notably increasing its original volume. For risk evaluation purposes, the evaluation of the potential path (i.e. the travel distance and the overall involved area) of a given debris flow is therefore an essential point.

The family " $S$ " of the Cellular Automata model SCIDDICA, originally developed for simulating flow-type landslides, has recently been realised in order to simulate the downslope evolution of a given soil slip-debris flow: in the model, the original landslide which originates along a slope is assumed to "immediately" turn into a flowing mass of debris (in CA terms, this occurs into the source cells during the first step of computation). By considering the availability of regolith, the process of erosion (and volume change) along the path of the simulated phenomenon can then be modelled. In $S_{3}$, this process has further on been improved with respect to the previous release (cf. Iovine et al., 2002): the erosion of the regolith is simulated in a progressive way, step by step, according to the energy of the flowing mass. By properly assigning values to the model parameters at the beginning of the simulation, the energy threshold to be overcome for soil erosion can be selected, as well as the factor of progressive erosion (this latter determines the thickness of soil cover which can be eroded at each step of computation). Accordingly, the regolith can now be eroded step by step, and cases of partial (incomplete) erosion can also be simulated.

The validation of the model for a particular study area is an essential phase: afterwards, the model can be "reliably" applied for predictive purposes - e.g. for evaluating the debrisflow susceptibility in a given study area. Note that the set of values for global parameters (as determined through validation) can only be utilised for applying the model to the same geologic context (or to a similar one), in order to simulate new landslides of the same type as those considered for validation.

In this paper, an example of application of SCIDDICA $S_{3-h e x}$ to the Vallicelle area of San Martino V. C. is considered. Preliminary results of calibration indicate that the predictive ability is quite satisfying, also in terms of indicators of error. The possibility of assessing, through a deterministic approach, the relative susceptibility to debris flows of the considered area is shown in Fig. 8: some sectors are affected by only one of the simulated landslides, while others are involved in more phenomena (up to seven). In the same zonation, areas involved into multiple phenomena are generally located at the base of the slope: the sector where one victim was caused during the December 1999 event resulted to be among the most susceptible to debris flows.

For simulating a given debris flow through SCIDDICA $S_{3-h e x}$, thickness of erodable soil cover and topographic information have to be given to the model, as input matrices. Location and extent of the landslide source must also be decided, on the basis of the geological s.l. knowledge of the area of study. In the analysis here presented, sources characters have been hypothesised by taking into consideration the statistics of a severe hydrogeological event, occurred in the study area on December 1999, and information related to previous landslide activations in the same zone. Moreover, other sources have been hypothesised on the base of a recent study on landslide risk in the study area, carried out by the Regional Authority (PAI - Hydrogeological setting plan, in press). The scenario adopted in the present study is therefore analogous to the Valle Caudina December 1999 event (or slightly worse): the results obtained by applying SCIDDICA $S_{3-h e x}$ refer to such a type of hydrogeological event. As in Fig. 8 only individual results (i.e. obtained by "independently" simulating one single case at a time) have been considered, the susceptibility zonation depicts a "minimum" scenario: the area involved by two adjacent contemporary flows can in fact be different (larger), if compared to individual results of simulation, owing to interference between the flowing masses.

With reference to the adopted set of values for global parameters, as obtained through calibration of the model in the Vallicelle study area, it should be stresses that they are quite similar to those previously determined for the southern slope of the Pizzo d'Alvano massif, located in the surroundings of Mt. Somma-Vesuvius (about $25 \mathrm{~km}$ eastward of Naples - cf. Fig. 1): it is a carbonate massif, overlain by a heterogeneous volcaniclastic cover, whose average slope (in the area considered for simulations) is generally smaller than $30^{\circ}$. On the other hand, in the Vallicelle zone the average slope is greater than $37^{\circ}$ : this difference in slope - together with the geotechnical properties of the volcaniclastic material and other geomorphologic peculiarities - could explain the observed differences in the set of optimal parameters (cf. Table 1, in which left and right columns refers to the Pizzo d'Alvano and Vallicelle study areas, respectively). In particular, the values determined for the two study zones are the same, except for the parameters $p_{m t}, p_{r l}$ and $p_{p e f}$ - which are strictly related to mechanisms of energy transmission and dissipation in the flowing material. Greater values of both the run-up loss $\left(p_{r l}\right)$ and the factor of progressive erosion $\left(p_{p e f}\right)$, together with a smaller value of the threshold for mobilisation of the soil cover $\left(p_{m t}\right)$, seem to be in good agreement with the observed lower relief energy which characterises the Vallicelle geomorphological context, with respect to the Pizzo d'Alvano one.

The methodological approach utilised in the present study for debris-flow susceptibility zonation could conveniently be applied for risk mitigation purposes. Moreover, by properly translating into $C A$ terms any planned remedial work, its presumed effect on the landslide evolution (and thus its oppor- 
tunity) could also be preventively assessed.

Acknowledgements. The family " $S$ " of SCIDDICA has been developed thanks to specific funding of Regione Campania (special thanks to M. Adinolfi and L. Monti). The authors are grateful to all the collaborators which participated in the development of the model. L. Merenda and G. Nardi coordinated the project, D. D'Ambrosio wrote the code, and several others helped in improving the approach through numerous interesting discussions.

\section{References}

Amanti, M., Chiessi, V., Conte, G., Pantaleone, A., Motteran, G., Pantaloni, M., Ventura, R., and Petrone, F.: Preliminary report on the hydrogeological events which struck Cervinara and San Martino in Valle Caudina (Avellino) on 15-16 December 1999, (in Italian), Servizio Geologico d'Italia, Tech. Report (available on line at: http://www.dstn.it/sgn), 1999.

Avolio, M. V., D’Ambrosio, D., Di Gregorio, S., Fata, R., Rongo, R., Spataro, W., Iovine, G., and Lupiano, V.: A cellular Automata model for different complexity landslides, in: Proc. $6^{\circ}$ Workshop di Informatica Applicata alle Scienze della Terra, edited by Nardi, G., and Vigliotti, M., Sansepolcro, 101-113, 1999.

Avolio, M. V., Di Gregorio, S., Mantovani, F., Pasuto, A., Rongo, R., Silvano, S., and Spataro, W.: Simulation of the 1992 Tessina landslide by a cellular automata model and future hazard scenarios, JAG, 2, 1, 41-50, 2000.

Barca, D., Di Gregorio, S., Nicoletta, F. P., and Sorriso-Valvo, M.: A Cellular Space Model for Flow type Landslides, in: Computers and their Application for Development, edited by Messina, G., and Hamzda, M.H., Proc. Int. Symp. IASTED, Taormina, 3032, 1986.

Cannon, S. H.: An evaluation of the travel-distance potential of debris flows, Utah Geological and Mineral Survey, Salt Lake City, Misc. Publ., 89-2, 1989.

Cannon, S. H. and Savage, W. Z.: A mass-change model for the estimation of debris-flow runout, J. Geology, 96, 221-227, 1988.

Clerici, A. and Perego, S.: Simulation of the Parma River blockage by the Corniglio landslide (northern Italy), Geomorphology, 33, 1-23, 2000.

D’Ambrosio, D., Di Gregorio, S., Iovine, G., Lupiano, V., Rongo, R., and Spataro, W.: First simulations of the Sarno debris flows through cellular automata modelling, Geomorphology, in press, 2003.

D’Ambrosio, D., Di Gregorio, S., Iovine, G., Lupiano, V., Merenda, L., Rongo, R., and Spataro, W.: Simulating the Curti-Sarno debris flow through Cellular Automata: the model SCIDDICA (release $S_{2}$ ), Phys. Chem. Earth, 27, 36, 1577-1585, 2002.

Del Prete, M., Guadagno, F. M., and Hawkins, A. B.: Preliminary report on the landslides of 5 May 1998, Campania, southern Italy, Bull. Eng. Geol. Env., 57, 113-129, 1998.

Di Gregorio, S., Nicoletta, F. P., Rongo, R., Sorriso-Valvo, M., Spataro, W., Spezzano, G., and Talia, D.: Landslide Simulation by Cellular Automata in a Parallel Environment, Proc. 2nd Int. Work./Massive Parallelism. Hardware, Software and Applic., Capri, 392-407, 1994.

Di Gregorio, S. and Serra, R.: An empirical method for modelling and simulating some complex macroscopic phenomena by cellular automata, Future Generation Computer Systems, 16, 259$271,1999$.
Di Gregorio, S., Rongo, R., Siciliano, C., Sorriso-Valvo, M., and Spataro, W.: Mt. Ontake landslide simulation by the cellular automata model SCIDDICA-3, Phys. Chem. Earth, 24, 2, 97-100, 1999.

Eisbacher, G. H., and Clague, J. J.: Destructive mass movement in high mountains: hazard and management, Geol. Surv. of Canada, Ottawa, 84-16, 1984.

Ellen, S. D.: Description and mechanics of soil slip/debris flows in the storms, in: Landslides, floods, and marine effects of the storms of 3-5 January 1982, in the San Francisco Bay Region, California, edited by Ellen, S. D. and Wieczorek, G. F., U.S. Geological Survey, Prof. Paper 1434, 63-112 (with contributions by: Algus, M. A., Cannon, S. H., Fleming, R. W., Lahr, P. C., Peterson, D. M., and Reneau, S. L.), 1988.

Fiorillo, F., Guadagno, F. M., Aquino, S., and De Blasio, A.: The December 1999 Cervinara landslides: further debris flows in the pyroclastic deposits of Campania (southern Italy), Bull. Eng. Geol. Env., 60, 171-184, 2001.

Iovine, G. and Di Gregorio, S.: SCIDDICA S2: considerations on applying a Cellular Automata model for simulating debris flows, (in Italian), Boll. Soc. Geol. It., in press, 2003.

Iovine, G., Di Gregorio, S., D’Ambrosio, D., and Lupiano, V.: Debris-flows and Cellular Automata: an example of simulation from the 1998 disaster of Sarno (Italy), in: Proceedings of the International Symposium "Geomorphology: from expert opinion to modelling", edited by Delahaye, D., Levoy, F., and Maquaire, O., Strasbourg, 26-27 April, 55-64, 2002.

Ippolito, F., D'Argenio, B., Pescatore, T. S., and Scandone, P.: Structural-stratigraphic units and tectonic framework of southern Apennines, Geology of Italy, Squyres, Tripoli, 317-328, 1975.

Johnson, A. M. and Rodine, J. R.: Debris flows, in: Slope Instability, edited by Brunsden, D., and Prior, D. B., John Wiley, New York, 257-361, 1984

Lirer, L., Pescatore, T. S., Booth, B., and Walker, G. P. L.: Two plinian pumice-fall deposits from Somma-Vesuvius, Italy, Geol. Soc. Am. Bull., 84, 759-792, 1973.

Malamud, B. D. and Turcotte, D. L.: Cellular Automata models applied to natural hazards, IEEE Computing in Science and Engineering, 2, 3, 42-51, 2000.

PAI - Hydrogeological setting plan, (in Italian), Regione Campania, Napoli, in press, available online: www.autoritadibacinonordoccidentale.campania.it

Petitot, J.: Centric/a-centric, (in Italian), in: Enciclopedia, Einaudi, Torino, 2, 894-954, 1977.

Rosi, M. and Sbrana, A.: The Campanian Ignibrite, in: Phlegrean Fields, edited by Rosi, M. and Sbrana, A., CNR-Quaderni della Ricerca Scientifica, 9, 114, 13-14, 1987.

Schuster, R. L. and Wieczorek, G. F.: Landslide triggers and types, in: Landslides, edited by Rybar, J, Stemberk, J., and Wagner, P., Proc. 1st European Conf. on Landslides, Prague, 24-26 June, 59-78, 2002.

Segre, E. and Deangeli, C.: Cellular Automaton for Realistic Modelling of Landslides, Nonl. Proc. Geophys., 2, 1, 1-15, 1995.

Toffoli, T.: Cellular Automata as an alternative to (rather than an approximation of) differential equations in modelling physics, Physica, 10, D, 117-127, 1984.

Varnes D. J. and IAEG Commission on Landslides: Landslide hazard zonation - a review of principles and practice, UNESCO, Natural Hazards Series, 3, Paris, 1984.

Vittori, E., Fumanti, F., Ligato, D. and Triglia, A.: Technical report on the surveying in the area affected by the hydrogeological crisis of 15-16 December 1999 in the Caudina Valley (Avellino), (in 
Italian), ANPA and ARPA Campania, Tech. Rep., 14 January, 2000 .

von Neumann, J.: Theory of self reproducing automata, Univ. of Illinois Press, 1966.

Wieczorek, G. F.: Landslide triggering mechanisms, in: Landslides: Investigation and Mitigation, edited by Turner, A. K., and Schus- ter, R. L., Special Report 247, 76-90, Transp. Res. Board, National Research Council, Nat. Acad. Press, Washington D. C., 1996.

Wolfram, S.: A new kind of Science, Wolfram Media Inc., Champaign, 2002. 